\title{
Effects of Heavy Metals on Plant Growths and Pigment Contents in Arabidopsis thaliana
}

\author{
Seung-A Baek ${ }^{1}$, Taejun Han ${ }^{1}$, Soon-Kil Ahn ${ }^{1}$,Hara Kang', Myung Rae Cho ${ }^{2}$, Suk-Chan Lee ${ }^{3}$ and \\ Kyung-Hoan Im $^{1 *}$ \\ ${ }^{1}$ Department of Biology, University of Incheon, Incheon 406-840, Korea \\ ${ }^{2}$ Pest Management Lab, National Institute of Horticultural \& Herbal Science, RDA, Suwon 441-440, Korea \\ ${ }^{3}$ Department of Genetic Engineering, Sungkyunkwan University, Suwon 440-746, Korea \\ (Received on January 10; Revised on August 2, 2012; Accepted on August 27, 2012)
}

The effect of heavy metals on seedling growth and pigment levels was studied in Arabidopsis using essential $(\mathrm{Cu}, \mathrm{Mn}$, and $\mathrm{Zn}$ ) and non-essential metals ( $\mathrm{Pb}$ and $\mathrm{Hg}$ ). Generally increasing the concentrations of the metals resulted in a gradual decrease in root and shoot lengths, a decrease in chlorophylls, an increase in anthocyanins and a fluctuation in carotenoid content depending on the metal types. The toxicity of the metals decreased in the following order: $\mathrm{Cu}>\mathrm{Hg}>\mathrm{Pb}>\mathrm{Zn}>\mathrm{Mn}$. Among the five metals, $\mathrm{Cu}$ was exceptionally toxic and the most potent inducer of anthocyanins. $\mathrm{Pb}$ induced the smallest quantity of anthocyanins but it was the strongest inducer of carotenoids. It suggests that the Cu-stressed Arabidopsis may use anthocyanins as its main antioxidants while the Pb-stressed Arabidopsis use carotenoids as its main protectants. All of the five metals induced an accumulation of anthocyanins. The consistent increase in anthocyanin content in the metal-stressed Arabidpsis indicates that anthocyanins play a major role in the protection against metal stresses.

Keywords : anthocyanins, Arabidopsis, carotenoids, heavy metals, pigment

Due to the development of modern industries, increasing amounts of heavy metals from mining, chemical, and metal processing industries have been accumulated in the soil. In addition to direct deposition of heavy metals in the soil, contaminated air can contribute to the formation of acid rain which can act upon the soil's chemistry, releasing heavy metals into the soil (Foy, 1984, 1988). Heavy metals released in the soil can be transferred and concentrated into plant tissues. Some heavy metals are essential for plants. Metals like $\mathrm{Cu}, \mathrm{Mn}$, and $\mathrm{Zn}$ fulfill essential roles as trace elements for physiological processes. $\mathrm{Cu}$ is required for the

\footnotetext{
*Corresponding author.

Phone) +82-32-835-8298, FAX) +82-32-835-4424

E-mail)khim61@incheon.ac.kr
}

photosynthetic generation of reducing power necessary for $\mathrm{CO}_{2}$ fixation, respiration, lignifications, and pollen formation. Mn plays an important role in the biosynthesis of chlorophylls and several enzymes along the isoprenoid pathway (Macfie and Taylor, 1992). Zn maintains the integrity of the membranes and regulates auxin synthesis (Alloway, 2008). Several heavy metals, such as $\mathrm{Pb}$ and $\mathrm{Hg}$, have no known physiological function and are highly toxic to cells, even at low concentrations (Valko et al., 2005). Regardless of the metal types, above certain concentrations and over a narrow range, heavy metals can turn into toxins, inhibit plant growth, and cause various physiological problems (Babich et al., 1982).

It is well documented that heavy-metal toxicity has an effect on seed germination, plant growth, and root elongation (Soudek et al., 2010; references therein). Metal toxicity is mediated through various mechanisms. Transition redox-active metals, like $\mathrm{Cu}$, interact directly with cellular oxygen resulting in the formation of reactive oxygen species (ROS) via Fentontype reactions (Halliwell and Gutteridge, 1986). Another mechanism of metal toxicity, which is valid for all metals, is related to their strong ability to bind sulphur, nitrogen, and oxygen atoms (Nieboer and Richardson, 1980). Heavy metals can bind cysteine residues in peptides and in low-molecular-weight compounds like glutathione. Consequently, exposure to metals is often associated with severe changes in the cell redox status, due to glutathione depletion. Finally, as many enzymes possess metallic cofactors, the replacement of one metal by another one results in a strong inhibition of their activity.

Regarding the metal effects on pigments, it is known that excessive heavy metal compounds reduce the performance of photosynthetic apparatus and promote a reduction in photosynthetic pigments. Generally various metals inhibit chlorophyll and carotenoid production in plants, although they affect the production of chlorophylls more than the production of carotenoids (Fargasova, 1998, 2001; Singh et al., 1996). Metals can also enhance carotenoid production 
depending on the metal type, concentration, and the plant species (Sinha et al., 2003). Anthocyanins can be produced in response to metal stresses (Hale et al., 2001). In Arabidopsis, $\mathrm{Cu}$ treatment results in anthocyanin accumulation (Collin et al., 2008). Carotenoids and anthocyanins are the main pigments known to be involved in protecting plant organs from stresses. Carotenoids are plant pigments that function as non-enzymatic antioxidants (Strzalka et al., 2003). They play an important role in the protection of chlorophyll pigments under stress conditions. Anthocyanins are also believed to protect plants from various types of stresses. They are produced in response to metal stresses (Hale et al., 2001) and believed to increase the antioxidant response of plants in order to uphold the regular physiological status against biotic or abiotic stresses (Neill et al., 2002).

Because various plants respond differently to heavy metal stresses depending on metal types, metal concentrations, and the duration of metal stresses, we tried to evaluate the effect of toxic metals on the growth and pigment levels in a model plant, Arabidopsis. So far there has been no extensive study on plant growth and especially on the changes in the pigment levels of Arabidopsis after it has been exposed to metal stresses. Li et al. (2005) studied the effects of several heavy metals on the seed germination and the seedling growth of Arabidopsis. Their research was focused on physiological changes during the early growth stage of seedlings. No research has been executed regarding the changes in the pigment composition of Arabidopsis. Because pigments are very important not only for photosynthesis, but also for protection from an adverse environment, we decided to examine the effects of heavy metals on pigment levels and to try to understand how Arabidopsis uses its various pigments to combat metal stresses. In this study, we chose three essential metals $(\mathrm{Cu}, \mathrm{Mn}$, and $\mathrm{Zn})$ and two nonessential metals $(\mathrm{Pb}$ and $\mathrm{Hg})$. We studied the physiological and chemical responses of the plant according to each metal treatment. Here we report our results and analyze the responses of Arabidopsis to metal stresses.

The heavy metal treatment and the measurement of plant growth. All of the heavy metal solutions were purchased from Junsei Chemical Co (Japan). Copper $(\mathrm{Cu})$ Manganese $(\mathrm{Mn})$, Lead $(\mathrm{Pb})$, and Zinc $(\mathrm{Zn})$ were in the form of a standard solution $(1 \mathrm{~g} / \mathrm{L})$. $\mathrm{Hg}$ was in the form of a mercuric chloride $\left(\mathrm{HgCl}_{2}, 1 \mathrm{~g} / \mathrm{L}\right)$. To observe the effects of the heavy metals on seedling growth, Arabidopsis seeds were germinated on sterilized $3 \mathrm{MM}$ gel-blot paper soaked with MS (Murashige and Skoog) liquid media containing each heavy metal with concentrations as given in the results. Adequate concentrations of the heavy metals for the experiments were decided through a preliminary test to get the best results. The seedling growth was observed after 8 days from sowing the seeds. The lengths of the roots and the shoots were measured for each individual seedling (40 seedlings for one treatment). The mean values were calculated. The significance of the differences was determined using the Tukey test with a $95 \%$ confidence interval.

Pigment quantification. The leaves of the 8 day-old seedlings grown on heavy metal treated plates were homogenized in $15 \mathrm{ml}$ of $100 \%$ methanol. The homogenate was filtered through two layer cheese cloths, and was centrifuged at $3000 \mathrm{~g}$ for ten minutes. The supernatant was separated and the absorbances were read at 470, 530, 653, $666 \mathrm{~nm}$ on a spectrophotometer. The total chlorophyll concentration was calculated utilizing the following formula: $\left(15.65 \mathrm{~A}_{666}-\right.$ $\left.7.34 \mathrm{~A}_{653}+27.05 \mathrm{~A}_{653}-11.21 \mathrm{~A}_{666}\right)$. The total carotenoid content was calculated using the following formula: $1000 \mathrm{~A}_{470^{-}}$ $2.86\left(15.65 \mathrm{~A}_{666}-7.34 \mathrm{~A}_{653}\right)-129.2\left(27.05 \mathrm{~A}_{653}-11.21 \mathrm{~A}_{666}\right) /$ 245 . The calculation formulas of both pigments were described in Wellburn (1994). The anthocyanin concentration was estimated as $\mathrm{A}_{530}-0.24 \mathrm{~A}_{653}$ following Murray and Hackett (1991). The total amount of each pigment was divided by the fresh weight $(\mathrm{g})$ of the leaf samples and represented as $\mu \mathrm{g} / \mathrm{gFW}$.

In the preliminary test, various concentrations of (heavy) metals were tested to find the adequate concentrations of heavy metals for the main experiments. Based on the preliminary test result, we applied different concentrations of metals to the seedlings. Depending on the increasing concentrations of metals, seedlings showed greater growth retardation, lost their green color and became yellowish (Fig. 1). The effect of the metals on seedling growth was evaluated by monitoring shoot and root growths. Root elongation was more sensitive than shoot growth to metals (Figs. 2 and 3). Generally, increasing amounts of metals resulted in the gradual decrease in root length (Fig. 2). Among the 5 metals, $\mathrm{Cu}$ and $\mathrm{Hg}$ were the most effective metals in inhibiting root growth, while $\mathrm{Mn}$ and $\mathrm{Zn}$ were the least toxic metals on the Arabidopsis seedlings (Fig. 2). The extent of root inhibition was in the order of $\mathrm{Cu}>\mathrm{Hg}>\mathrm{Pb}>$ $\mathrm{Zn}>\mathrm{Mn}$ (Fig. 2). Despite general growth inhibition of the seedlings by increasing metal concentrations, some metals such as $\mathrm{Mn}$ and $\mathrm{Hg}$ stimulated root growth at low concentrations. Mn was especially effective in promoting root growth at 300-600 $\mu \mathrm{M}$, which when concentrations of other metals were significantly effective in inhibiting root growth.

Generally exposure of the seedlings to metals resulted in a reduction of their total chlorophyll content (Fig. 4). However, each metal showed different reduction rate of chlorophylls. $\mathrm{Zn}$ and Mn resulted in the most drastic reduction of chlorophylls depending on an increasing concentration of metals. Increasing amount of $\mathrm{Cu}, \mathrm{Hg}$, and $\mathrm{Pb}$ resulted in a 

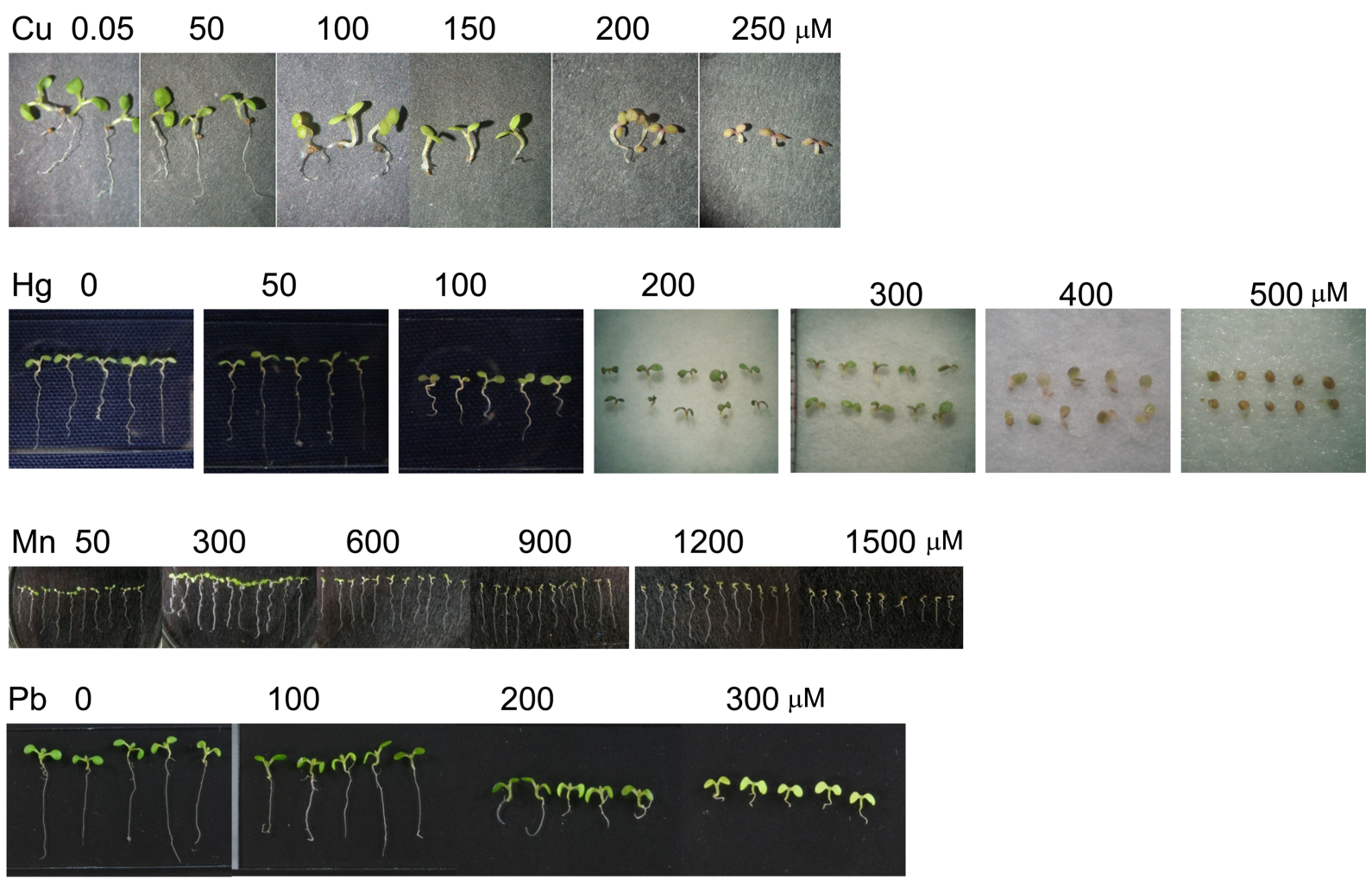

100

200

$300 \mu \mathrm{M}$
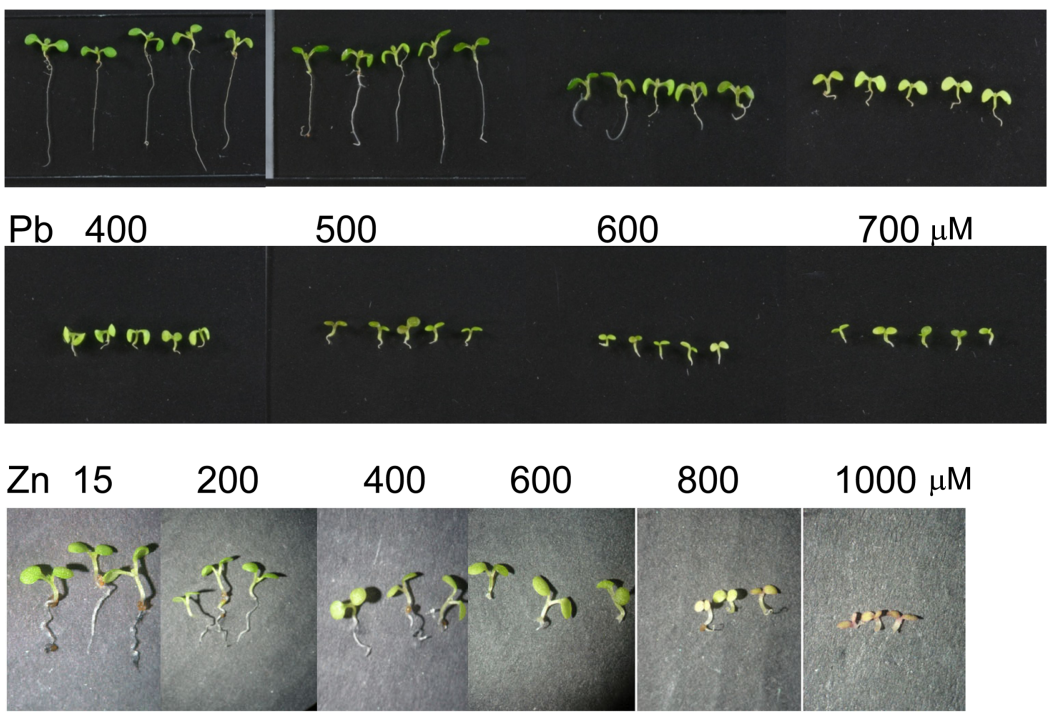

Fig. 1. Effects of heavy metals on seedling growth. Arabidopsis seeds were germinated and cultivated on MS medium of different concentrations of various heavy metals. Photographs were taken 8 days after sowing.

more gradual reduction in the chlorophyll content. Especially $\mathrm{Pb}$, which was the most ineffective at inhibiting chlorophyll accumulation compared to the other metals. The seedling treatment with a low concentration of $\mathrm{Cu}(50 \mu \mathrm{M})$ resulted in an increased accumulation of chlorophylls but a subsequent increase in $\mathrm{Cu}$ concentration caused a gradual loss of chlorophyll content.

Arabidopsis showed the most varied response in carotenoid content to the metal treatments. Gradual increases and subsequent decreases of carotenoid content, depending on increasing concentrations of metals, were observed in $\mathrm{Cu}$ and $\mathrm{Hg}$-treated seedlings. In the case of $\mathrm{Mn}$ and $\mathrm{Zn}$, the opposite effect was observed. Caroteniod levels gradually decreased and then increased through treatments with increasing amounts of metals (Fig. 5). Pb-treated seedlings showed a different response. The carotenoid level was relatively constant from 0 to $600 \mu \mathrm{M} \mathrm{Pb}$ treatments, but the carotenoid level more than doubled at a $700 \mu \mathrm{M}$ treatment (Fig. 5).

All five of the metals resulted in an anthocyanin accumulation. An increase in metal concentration brought a higher accumulation of anthocyanins in the seedlings (Fig. 6). However, the mode of pigment accumulation was different depending on the metal types. $\mathrm{Cu}$ was the most effective in causing an anthocyanin accumulation. Compared to the control (0.05 $\mu \mathrm{M}$ treatment, $1.7 \mu \mathrm{g} / \mathrm{gFW}$ of anthocyanin), 


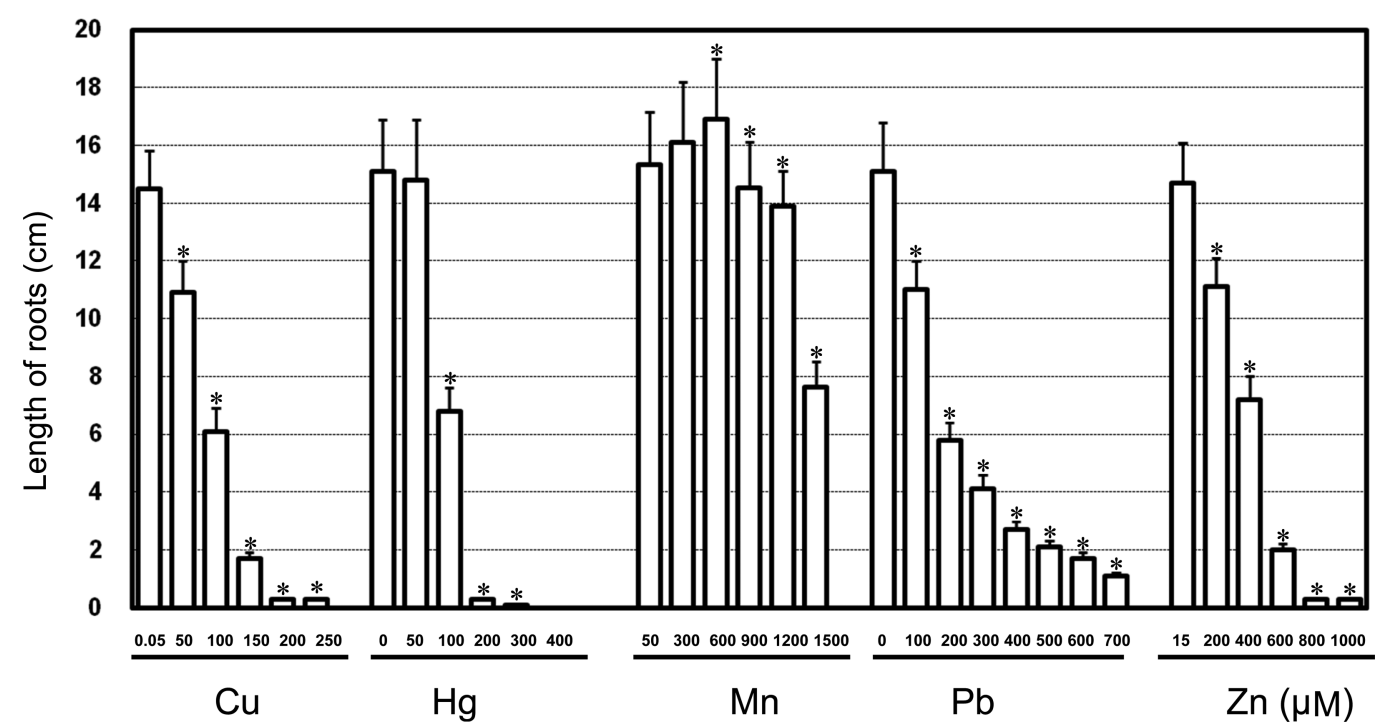

Fig. 2. Average length of roots of 8-day-old seedlings grown on various heavy metals. Forty samples were counted for each treatment. An asterisk on the bar means statistical difference at $\mathrm{p}<0.05$.

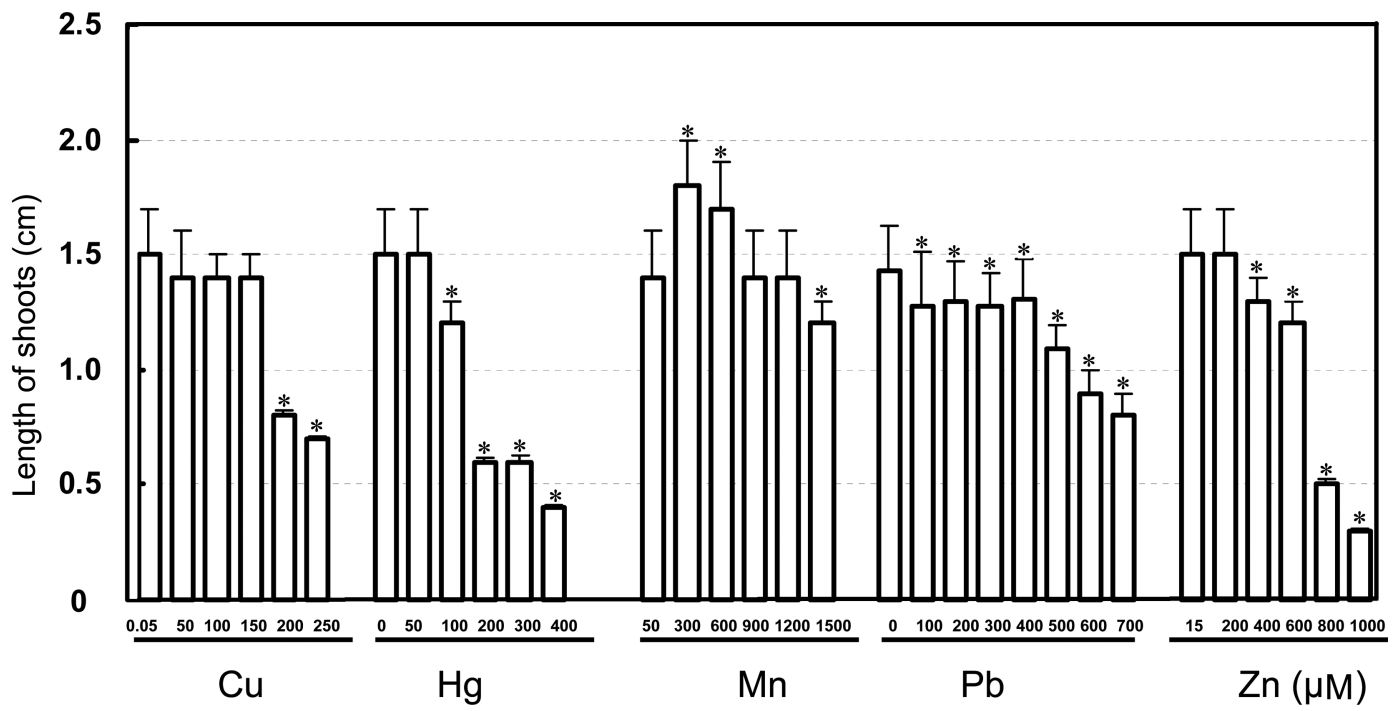

Fig. 3. Average length of shoots of 8-day-old seedlings grown on heavy metals. An asterisk on the bar means statistical difference at $\mathrm{p}<$ 0.05 .

$250 \mu \mathrm{M} \mathrm{Cu}$-treatment caused 19 times more accumulation of anthocyanin $(32.5 \mu \mathrm{g} / \mathrm{gFW})$. Pb was the least effective in causing an anthocyanin accumulation. However, a $700 \mu \mathrm{M}$ $\mathrm{Pb}$ treatment still resulted in 5-times more accumulation of anthocyanins compared to the untreated control (Fig. 6), indicating that anthocyanins were the most consistently accumulated through increasing amount of metals regardless of the metal type. The order of the metals causing more drastic kinetics of anthocyanin accumulation was $\mathrm{Cu}>\mathrm{Hg}$ $>\mathrm{Mn}>\mathrm{Zn}>\mathrm{Pb}$ (Fig. 6).

We examined the effects of the selected heavy metals on growth and pigment content in Arabidopsis. A similar research study was done with a model plant, Arabidopsis
(Li et al., 2005). However, in their study, the focus was mostly on the effects of the metals on plant germination and growth. In the present study, we tried to find out how plants respond to the different metals during plant growth, as well as discover their pigment levels because it is believed that plants will respond differently to excessive metals depending on the metal type. Through this research, we reached these conclusions: 1) In general, all metal stresses applied in the experiment resulted in a growth retardation of the root and shoot and a reduction in chlorophyll content, which is well documented in plants that have been treated with excessive metals (Fargasova 1998, 2001; Singh et al., 1996). 2) Every metal tested showed different toxic effects 


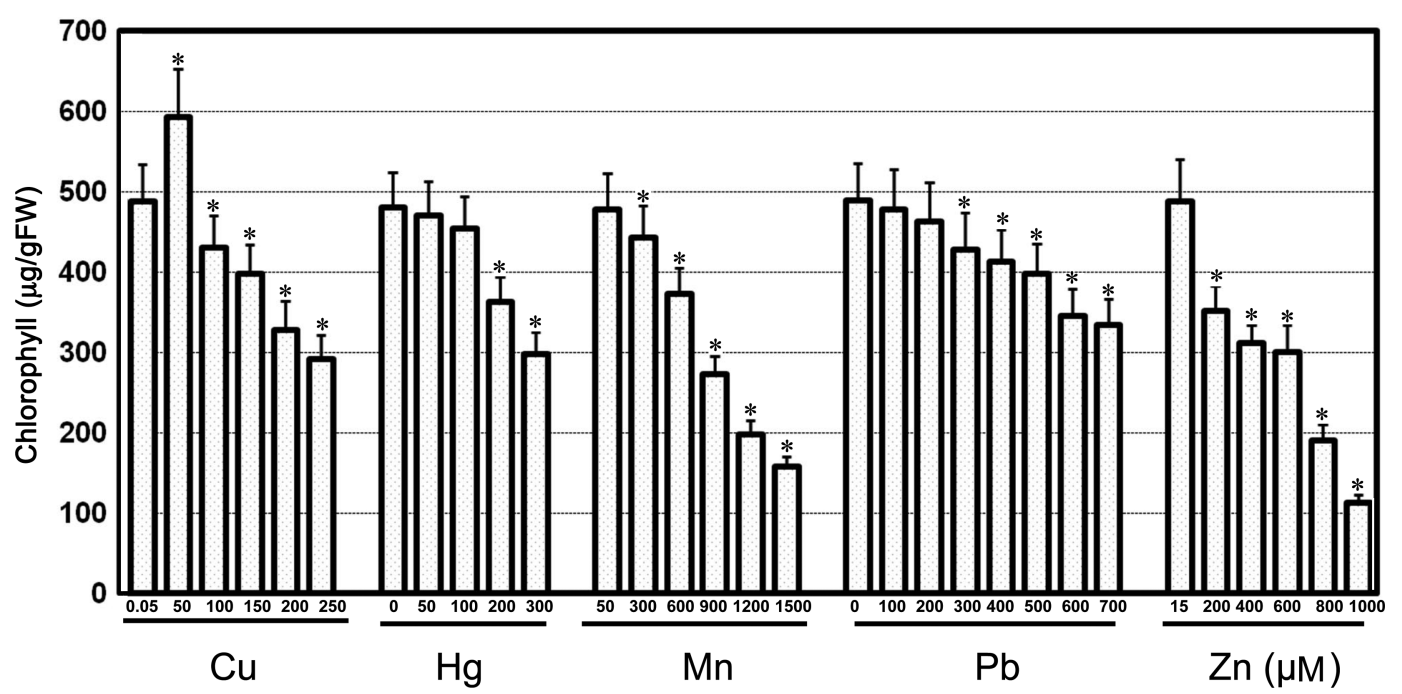

Fig. 4. The amount of chlorophyll depending on the level of heavy metals on Arabidopsis thaliana. An asterisk on the bar means statistical difference at $\mathrm{p}<0.05$.

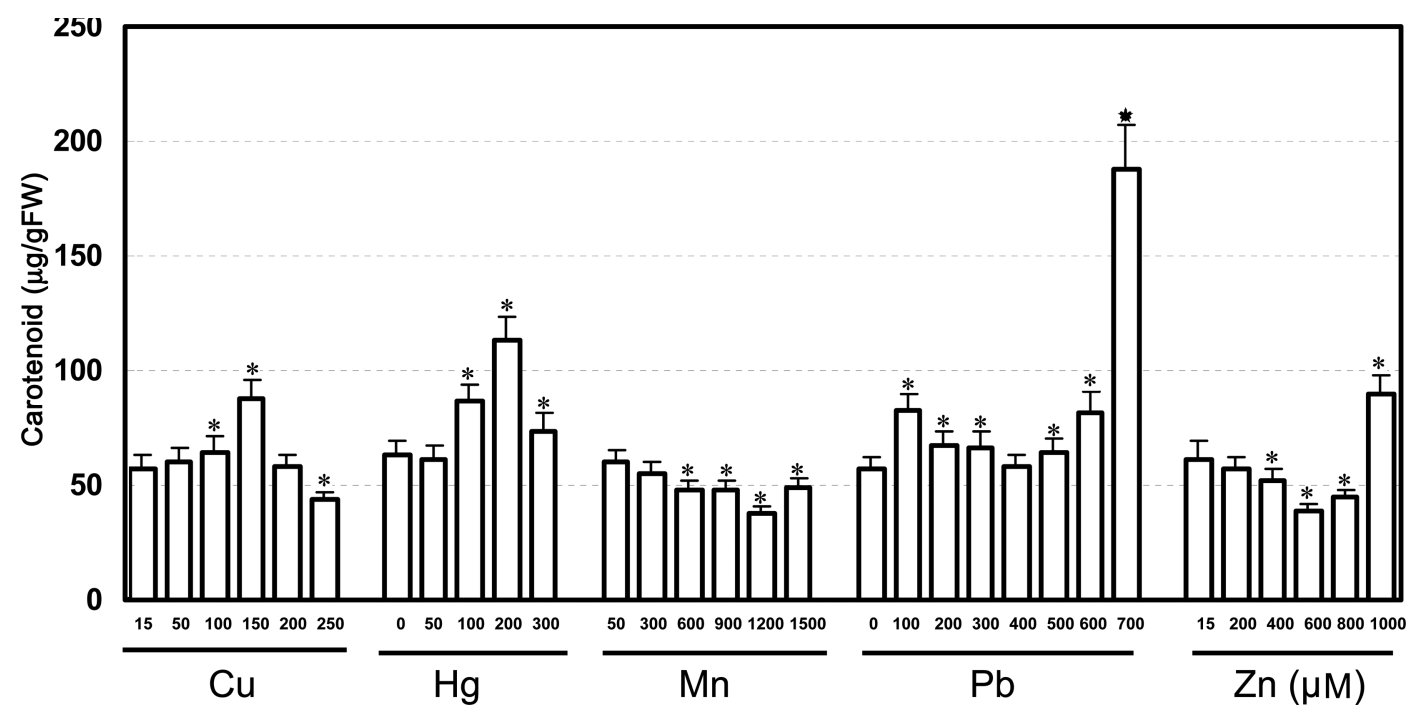

Fig. 5. The amount of carotenoid depending on the level of heavy metals on Arabidopsis thaliana. An asterisk on the bar means statistical difference at $\mathrm{p}<0.05$.

on Arabidopsis plants. Based on growth inhibition (Figs. 13 ), the order of the most toxic to the least toxic metals is $\mathrm{Cu}$ $>\mathrm{Hg}>\mathrm{Pb}>\mathrm{Mn}>\mathrm{Zn}$. 3) All of the metals induced similar trends, except with the plants' carotenoid content. In contrast to an inhibition of root elongation, chlorophyll reduction, and anthocyanin accumulation by increasing the metal concentrations, the carotenoid content increased or decreased depending on metal types. 4) Generally essential metals were less toxic than non-essential metals. However, $\mathrm{Cu}$ is exceptional. Even though $\mathrm{Cu}$ is an essential metal, it showed the most toxic effect on seedlings. It also significantly increased chlorophyll levels at $50 \mu \mathrm{M}$, this phenomenon was not observed from plant treated with other metals. In addition, $\mathrm{Cu}$ was the most potent inducer of anthocyanins, indicating that anthocyanins may play a major role in the protection of Cu-stressed plants. 5) In contrary to $\mathrm{Cu}, \mathrm{Pb}$ (a non-essential metal) induced the least amount of anthocyanins but the highest amount of carotenoids. $\mathrm{Pb}$ at $700 \mu \mathrm{M}$, induced 2 times more carotenoids than $\mathrm{Cu}$ at $150 \mu \mathrm{M}$, which showed the highest induction of carotenoids among $\mathrm{Cu}$ treatments (Fig. 5). Thus it indicates that Arabidopsis uses different defense mechanisms to combat different types of metal stresses. For example, the $\mathrm{Cu}$-stressed plants may use anthocyanins as their main antioxidants while the $\mathrm{Pb}$-stressed plants use carotenoids as their main protectants and anthocyanins as secondary pro- 


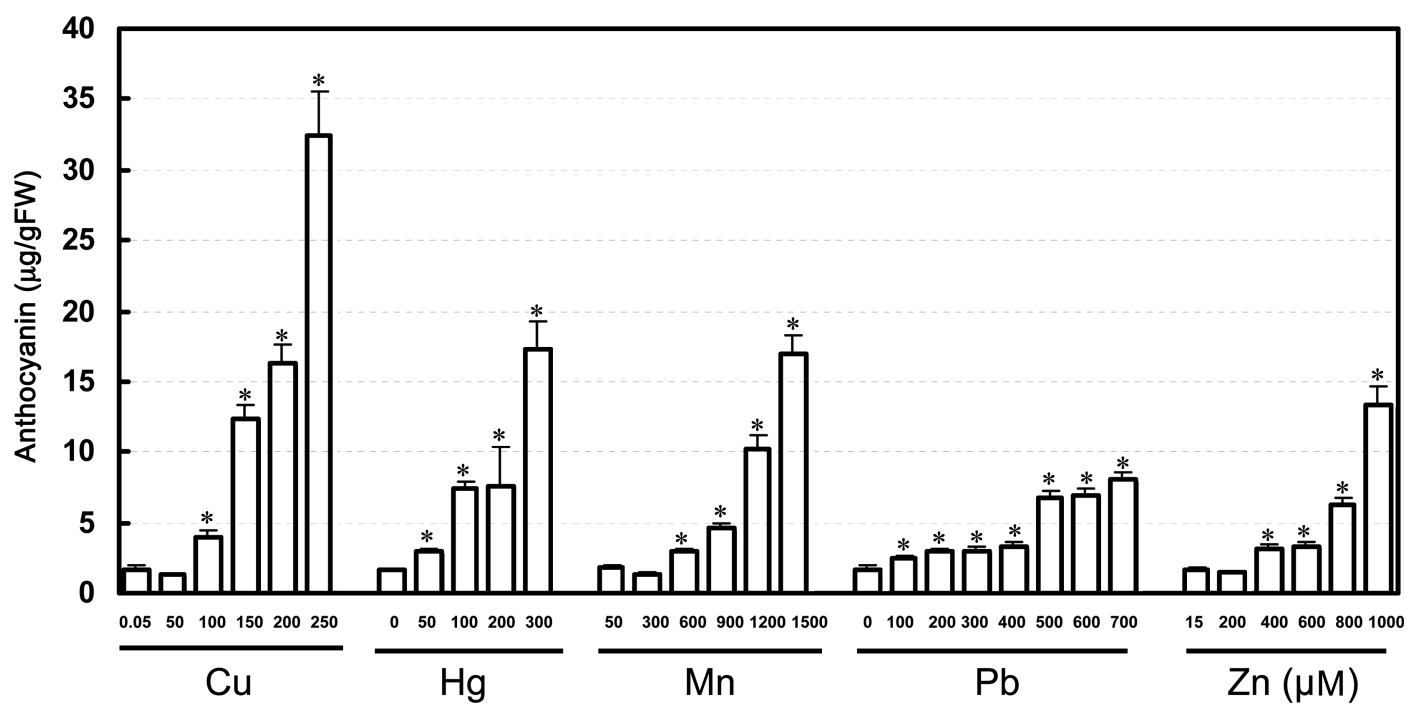

Fig. 6. The amount of anthocyanin depending on the level of heavy metals on Arabidopsis thaliana. An asterisk on the bar means statistical difference at $\mathrm{p}<0.05$.

tectants. 6) All of the 5 metal treatments induced the accumulation of anthocyanins. The higher the concentration of the metal, the more anthocyanins were proven to be accumulated.

Carotenoids and anthocyanins are the main pigments known to be involved with protecting plant organs from stresses. Metals can enhance or reduce carotenoid production depending on metal types (Fargasova, 1998; Sinha et al., 2003). Anthocyanins are produced in response to some metal stresses (Hale et al., 2001) and believed to increase the antioxidant response of plants (Neill et al., 2002). Thus, a consistent increase in anthocyanin content in metal-stressed Arabidopsis indicates that anthocyanins play a major role in the protection against metal stresses. The role of anthocyanins may be especially critical in highly stressed conditions. However, the role of carotenoids during metal stress seems to be more limited than anthocyanins except in plants that are exposed to $\mathrm{Pb}$, in which case carotenoid content increased according to the increased concentration of the metal. Carotenoids known to protect chlorophyll pigments under stress conditions may be produced less or less stable depending on the increase of metal concentrations. Thus, it seems that carotenoids play an important role in the protection against mild metal stress conditions. However, when the increasing concentration of metals provides more severe stresses, anthocyanins participate more actively in plant protection. Thus, depending on the metal type, plant may choose different defense systems. Anthocyanins from Perilla pankinensis are known to have strong antioxidant activity, reducing power, superoxide anion scavenging, hydrogen peroxide scavenging, and metal chelating activities (GulCin et al., 2005). It is also known that heavy metals can lead to oxygen free radical formation (Dietz et al., 1999). Thus, consistently increasing amounts of anthocyanins under heavy metal stresses suggest that anthocyanins play a role in the detoxification of heavy metal toxicities. In addition, anthocyanin may play a more important role with especially heavily metal-stressed plants than carotenoids. However, the biochemical study to elucidate the exact mechanism of the anthocyanin function in heavy metal-stressed plants has to be followed in the future.

\section{Acknowledgment}

This work was supported by the University of Incheon Research Grant in 2010 to KH Im.

\section{References}

Alloway, B. J. 2008. Zinc in Soils and Crop Nutrition. 2nd edition, IZA and IFA, Brussels, Belgium and Paris, France.

Babich, H., Schiffenbauer, M. and Stotzky, G. 1982. Comparative toxicity of trivalent and hexavalent chromium to fungi. Bull. Environ. Contam. Toxico. 28:193-202.

Collin, V. C., Eymery, F., Genty, B., Rey, P. and Havaux, M. 2008. Vitamin E is essential for the tolerance of Arabidopsis thaliana to metal-induced oxidative stress. Plant Cell Environ. 31:244-257.

Dietz, K. J., Baier, M. and Kramer, U. 1999. Free radicals and reactive oxygen species as mediator of heavy metal toxicity in plants. In: Prasad MNV, Hagemeyer J (eds), Heavy metal stress in plants: From molecules to ecosystem, pp.73-79. Springer - Verlag, Berlin, Germany.

Fargašová, A. 1998. Root growth inhibition, photosynthetic pig- 
ments production, and metal accumulation in Sinapis alba as the parameters for trace metals effects determination. Bull. Environ. Contam. Toxicol. 61:762-769.

Fargašová, A. 2001. Phytotoxic effects of $\mathrm{Cd}, \mathrm{Zn}, \mathrm{Pd}, \mathrm{Cu}$, and $\mathrm{Fe}$ on Sinapis alba L. seedlings and their accumulation in roots and shoots. Biol. Plantarum. 44:471-473.

Foy, C. D. 1984. Physiological effects of hydrogen, aluminum and manganese toxicities in acid soil. In: Soil Acidity and Liming, ed. by R. W. Pearson and F. Adams, pp. 57-97. Amer. Soc. Agronomy, Madison, Wisconsin, USA.

Foy, C. D. 1988. Plant adaptation to acid, aluminum-toxic soils. Commun. Soil Sci. Plant Anal. 19:959-987.

GulCin, I., Berashvili, D. and Gepdiremen, A. 2005. Antiradical and antioxidant activity of total anthocyanins from Perilla pankinensis decne. J. Ethnopharmacol. 101:287-293.

Hale, K. L., McGrath, S. P., Lombi, E., Stack, S. M., Terry, N., Pickering, I. J., George, G. N. and Pilon-Smits, E. A. H. 2001. Molybdenum sequestration in Brassica species. A role for anthocyanins? Plant Physiol. 126:1391-1402.

Halliwell, B. and Gutteridge, J. M. C. 1986. Oxygen free radicals and iron in relation to biology and medicine: some problems and concepts. Arch. Biochem. Biophys. 246:501-514.

Li, W., Khan, M. A., Yamaguchi, S. and Kamiya, Y. 2005. Effects of heavy metals on seed germination and early seedling growth of Arabidopsis thaliana. Plant Growth Regul. 46:4550 .

Macfie, S. M. and Taylor, G. J. 1992. The effects of excess manganese on photosynthetic rate and concentration of chlorophyll in Triticum aestivum grown in solution culture. Physiol. Plant 85:467-475.

Murray, J. R. and Hackett, W. P. 1991. Dihydroflavonol reductase activity in relation to differential anthocyanins accumulation in juvenile and mature phase Hedera helix L. Plant Physiol.
97: 343-351.

Nieboer, E. and Richardson, D. H. S. 1980. The replacement of the nondescript term "heavy metals" by a biologically and chemically significant classification of metal ions. Environ. Pollut. 1:3-26.

Neill, S. O., Gould, K. S., Kilmartin, P. A., Mitchell, K. A. and Markham, K. R. 2002. Antioxidant activities of red versus green leaves in Elatostema rugosum. Plant Cell Environ. 25:539-547.

Singh, R. P., Dabas, S. and Choudhary, A. 1996. Recovery of $\mathrm{Pb} 2+$ caused inhibition of chlorophyll biosynthesis in leaves of Vigna radiata (L.) Wilczek by inorganic salts. Indian J. Exp. Biol. 34:1129-1132.

Sinha, S., Bhatt, K., Pandey, K., Singh, S. and Saxena, R. 2003. Interactive metal accumulation and its toxic effects under repeated exposure in submerged plant Najas indica. Cham. Bull. Environ. Contam. Toxicol. 70:696-704.

Soudek, P., Katrusáková, A., Sedlácek, L., Petrová, S., Kocí, V., Marsík, P., Griga, M. and Vanek, T. 2010. Effect of heavy metals on inhibition of root elongation in 23 cultivars of flax (Linum usitatissimum L.). Arch. Environ. Contam. Toxicol. 59:194-203.

Strzalka, K., Kostecka-Gugała, A. and Latowski, D. 2003. Carotenoids and environmental stress in plants: significance of carotenoid-mediated modulation of membrane physical properties. Russ. J. Plant. Physl. 50:168-172.

Valko, M., Morris, H. and Cronin, M. T. 2005. Metals, toxicity and oxidative stress. Curr. Med. Chem. 12:1161-1208.

Wellburn, A. R. 1994. The spectral determination of chlorophylls $a$ and $b$, as well as total carotenoids, using various solvents with spectrophotometers of different resolution. J. Plant Physiol. 144:307-313. 